\title{
Formation of local temperature regime in the room: personal ventilation system
}

\author{
Andrey Rymarov*, Pavel Havanov, and Dmitri Titkov \\ Moscow State University of Civil Engineering, Yaroslavskoe shosse, 26, Moscow, 129337, Russia
}

\begin{abstract}
The peculiarities of a person's metabolism are related to the state of health, age, and other personality traits, which determines the need for a personal value of the ambient air temperature. Individualization of work and recreation of people requires the creation of local temperature zones in the room with the air temperature necessary for a particular person, which will increase labor productivity, reduce morbidity, since the stress of the human thermoregulation system will be minimal. In addition, the personalization of the microclimate in the workplace in the room with the creation of local temperature zones will allow you not to waste heat and electricity where it is not needed, creating additional opportunities for energy saving potential in the premises of the building. The article deals with the personalization of the operation of the ventilation system in the room with the formation of vertical conical air jets coming from the ceiling of the room to the workplace, considering the requirements of regulatory documents for the air velocity in the working area of the room.
\end{abstract}

\section{Introduction}

This article discusses the use of air jets of the ventilation and air conditioning system to create comfortable local temperature zones in the workplace in an office space. The need to form a person's personal space in the room at the workplace has an important socio-cultural significance [1-4].

Quite recently, a workplace in an office is a space for a chair and a desk with the minimum necessary equipment, and today a workplace is a high-tech space with all the necessary infrastructure: with office equipment, with special furniture and equipment to create the necessary microclimate parameters. Intensive work for 6-8 hours in the office requires creating all types of motivation for a person and increasing all the components of comfort. Personalization of ventilation systems allows local air supply in the required quantity and with the required parameters for each workplace in the office space $[5,6]$. People differ in age, health status and other features, and the parameters of the supply air for each person must be adjusted individually, and this primarily relates to the air temperature. In this case, with the help of the ventilation system, local temperature zones of individual comfort are formed in the room.

\footnotetext{
* Corresponding author: rymarovag@mgsu.ru
} 


\section{Problem statement}

A high-tech space for a working or resting person must adapt to the needs of each person in specific microclimate parameters, which will increase his productivity or the quality of rest. With such an organization of air exchange with local ventilation for each workplace, general exchange forced ventilation delivers air to the room in the amount necessary for assimilation of thermal surpluses from all heat sources in the room, and local ventilation with air exchange for each workplace supplies air in an amount equal to the number for a person's stay at the workplace for more than 2 hours and is equal to $60 \mathrm{~m} 3$ / hour per workplace. The sum of the total supply air and local supply air for 6 workplaces is equal to the total extract from the room, taking into account the required balance. At the same time, the exhaust ventilation will have to adapt to the existing supply air to the workplaces, since empty or temporarily unoccupied workplaces can be left without fresh air supply, thus the overall balance in the amount of supply and extract air will be observed, and the thermal and electrical energy systems ventilation will not be wasted unnecessarily.

Under these conditions, it is possible to create local zones at each workplace with a slight difference in air temperature from the average value in the room. Under these conditions, it is possible to create local zones at each workplace with a difference in air temperature from the average value in the room.

The thermal regime in the room is formed due to the flow of heat from the jets of local ventilation systems, which give heat to the room as air heating and due to the operation of the general ventilation system and known sources of heat at appropriate rates of heat loss. In the absence of people in the room, the local ventilation systems can be set to air heating with the minimum required temperature in the room.

The local microclimate at workplaces in this formulation of the problem is formed due to the flow of heat from local ventilation systems.

The supply jets directed downward from the ceiling to the workplace when interacting with the room air will form the average room temperature.

To calculate the thermal balance of a room, the resistance to heat transfer of external enclosing structures is used. The temperature and air velocity in the cross-section of the supply jets of the local ventilation systems were calculated based on the data of Professor I.A. Shepelev. [7]. The influence of the inertia of the thermal regime [8,9] of the building envelope on the microclimate [10] was not taken into account.

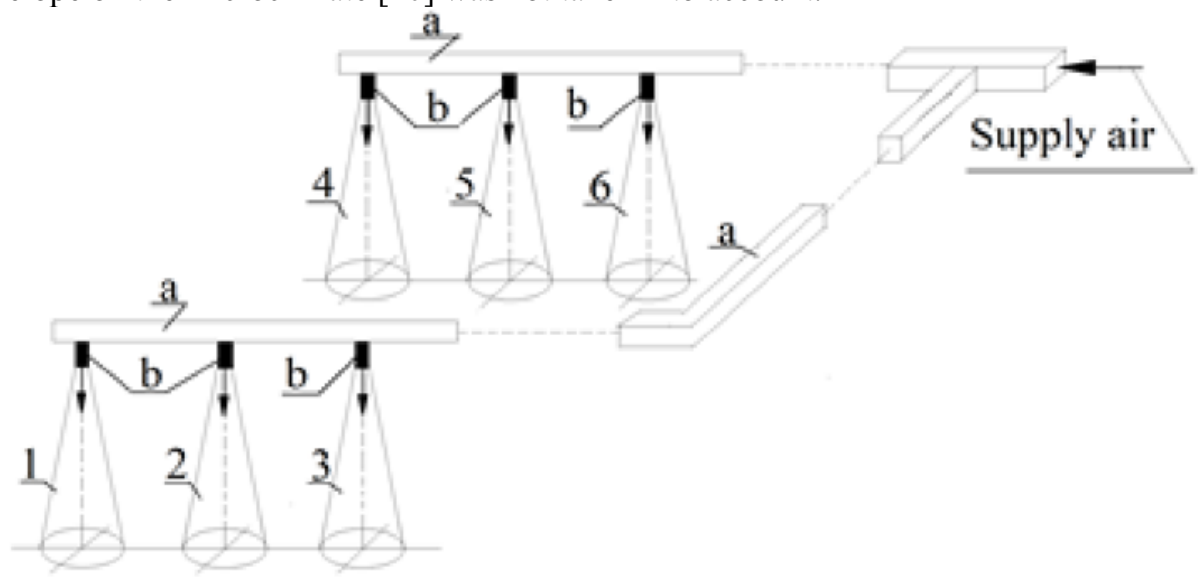

Fig. 1. Model of the formation of conical jets (1-6) for servicing 6 workplaces in an office space (a supply air ducts, $\mathrm{b}$ - air distribution units). 


\section{Result of calculation}

As an illustrative example, consider an office space with dimensions of $6 \times 5 \mathrm{~m}$ and a height of $3.5 \mathrm{~m}$. The room has one window with an area of $4.5 \mathrm{~m} 2$ and one outer wall with an area of $16.5 \mathrm{~m}^{2}$. Calculations of the heat balance of a room for the cold season for the city of Moscow, as well as calculations of the parameters of local jets have been carried out. The complexity of monitoring the parameters of the microclimate in the room $[11,12]$ allows you to control the air temperature in the local supply jets at the request of workers. We form 6 individual zones in the room with the ability to create in them the temperature required by a specific employee. Air heating is provided in the room, implemented by local air jets, serving individually workplaces (Fig. 1) and which create an average temperature in the room equal to $17.7^{\circ} \mathrm{C}$, and also heat up the air at 6 workplaces to the following values: $18^{\circ} \mathrm{C}, 18,8^{\circ} \mathrm{C}$, $19,7^{\circ} \mathrm{C}, 20,7^{\circ} \mathrm{C}, 21,8^{\circ} \mathrm{C}, 22,8^{\circ} \mathrm{C}$. The results of calculations of changes in velocity and temperature on the axis of local jets are shown in Fig. 2 and 3.

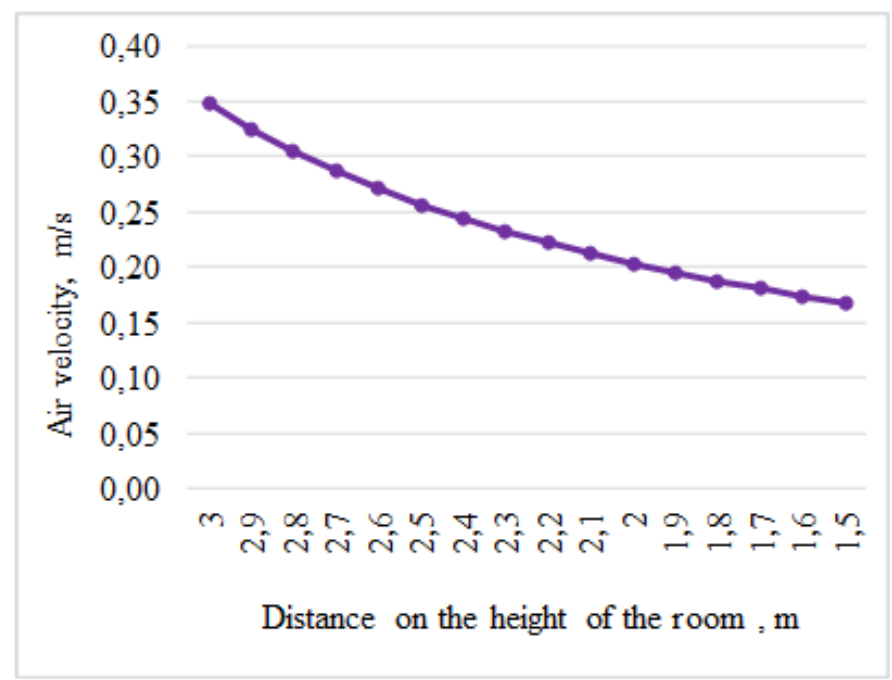

Fig. 2. Estimated change in speed on the axis of the supply jet serving a workplace in an office building.

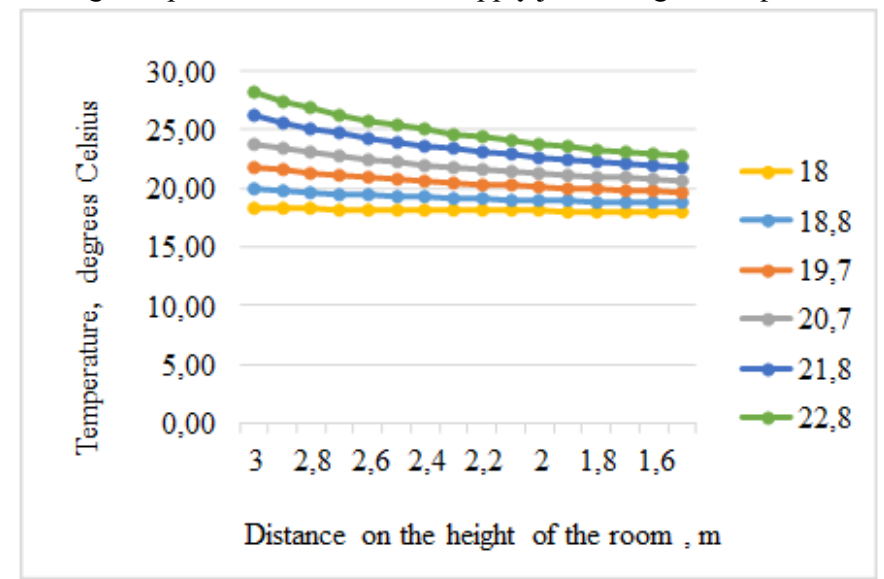

Fig. 3. Estimated change in air temperature on the axis of 6 supply jets serving 6 workplaces in an office building. 
The supply jet coming from the ceiling of the room to the individual workplace must meet the following requirements: the speed on the jet axis at the entrance to the working area of the room must be equal to no more than $0.15-0.2 \mathrm{~m} / \mathrm{s}$, the air temperature in the jet must be is equal to that which is necessary for the employee in the specified range, the jet should serve the floor area of the office space close to the area of the individual workplace.

Pretreated air with parameters for general ventilation enters the air duct (a) passing under the ceiling of the room, and then through the air distribution unit (b) with the required parameters is supplied to the workplaces (Fig. 1). The air distribution unit must warm up in the cold season or cool the air in the warm season to the temperature required by a particular worker at the workplace. The air distribution unit is a high-tech device capable of bringing the parameters of the local supply air to the required values for each workplace and supplying air to the working area of the room at the required speed while maintaining the required air mobility. The jet coming out of the $200 \mathrm{~mm}$ inlet opening under the ceiling of the room at a height of $\mathrm{h}=3 \mathrm{~m}$ expands as it moves to the working area and its diameter near the floor of the room is about $1.5 \mathrm{~m}$ (excluding some difference in the opening of the flooded jet with a slight difference between the initial temperature of the air in the jet and the temperature of the ambient air, which lead to an increase in the angle that increases the volume of the jet), the calculated area of the workplace is approximately $5 \mathrm{~m} 2$ or conditionally corresponds to an equivalent square with a side of $2.2 \mathrm{~m}$, which allows us to say that the jet covers the chair with its influence with a man at the workplace.

On the example of the balance calculation of the air-thermal regime, the possibility of the formation of local zones at workplaces indoors is shown. The general formulation of the study is not aimed at the development of technical devices and only demonstrates the capabilities of local ventilation systems (jet). The use of such systems, in a somewhat simplified formulation, has received in the systems of organizing the air-thermal regime in the aircraft cabins, various kinds of air-thermal curtains, devices of local supply ventilation at workplaces, etc.

Further development of the technical base in the development of systems and approaches to the formation of local zones of the air-thermal regime in various types of premises will create comfortable conditions at the workplace.

Energy saving in multi-apartment buildings in the formation of the microclimate is actively engaged in Russia [13], including the search for activation of the natural ventilation system [14]. The organization of living spaces, considering the possibilities for organizing a more comfortable environment and the formation of a microclimate in them, is an important topic of our time $[15,16]$. The formation of a habitat with the best characteristics of ventilation systems allows you to saturate the air with oxygen and form the desired air-ion regime in the premises $[17,18]$. The climate of the globe is constantly changing and periods of unstable temperatures, including low ones, take place, which affects the operation of systems that form the microclimate $[19,20]$.

\section{Conclusions}

1. The air distribution unit, capable of forming descending jets with air speed and temperature, which vary along the length of the jet within a given range, is similar to self-contained ceiling-type devices for supplying supply air to HOVAL premises.

2. In the analysis of the work of local jets, the factor of mutual influence of jets and individual local zones is not taken into account, especially over time when the air in the room is mixed.

3. Considered in this article as an example, vertical jets of a conical type with air movement from top to bottom can be replaced with other types of jets with other air exchange 
schemes, which can also form the localization of the microclimate at the workplace in the room.

4. The implementation of local modes with a variety of temperature preferences of people cannot be applied in small-volume rooms, since air mixing will lead to an equalization of the temperature regime in the room, which means that more spacious and larger rooms are suitable.

\section{References}

1. Paderin V. K., Mitroshina O. V., Gatin I. D., Individual space as an object of sociological analysis: towards the problem statement. Kazan socio-humanitarian Bulletin vol. 5 (28). pp. 69-73 (2017)

2. Alieva E. M., Dynamics of changes in the individual educational space of junior schoolchildren in the process of self-knowledge. Problem of modern pedagogical education vol. 67-1, pp. 282-286 (2020)

3. Bezukladova I. Yu., Categorization of individual space as a way of structuring the surrounding world. Bulletin of the Tambov University. Series: Humanitarian Sciences vol. 7 (99), pp. 153-159 (2011)

4. Naumova O. B., Private space in the system of values of traditional society. Ethnographic review vol. 4, pp. 77-93 (2014)

5. Bodrov M. V., Kuzin V. Yu., Morozov M. S., Computational justification of the limits of the operating modes of natural and hybrid ventilation systems. Plumbing, Heating and Air Conditioning. vol. 1(169), pp. 74-77 (2016)

6. Rymarov, A.G., Agafonova, V.V., Air supply device to the worker's breathing zone. Materials Science Forum, 931 MSF, pp. 897-900 (2018)

7. Shepelev, I.A., The aerodynamics of the airflow in the room. Moscow, Stroizdat. p. 144 (1978)

8. Brukhanov O., Rymarov A., Malysheva A., Titkov D., Analysis of heat losses of underground tunnel for engineering utilities with available methods. MATEC Web of Conferences pp. 04028 (2016)

9. Rymarov A.G., Davidsson H., Analysis of heat losses in underground tunnels for preheating of ventilation air. International Journal of Civil Engineering and Technology. vol. 8. 11, pp. 1172-1180 (2017)

10. Bodrov V. I., Bodrov M. V., Smykov A. A., Investigation of the thermal regime of external enclosing structures in industrial premises with heating systems based on infrared emitters. Volzhsky scientific journal.. vol. 2 (46). pp. 29-36. (2018)

11. Rymarov A.G., Monitoring of microclimate parameters and concentrations of harmful impurities in the premises of the building. Volzhsky scientific journal vol. 1 (29), pp. 6163 (2014)

12. Bodrov M. V., Kuzin V. Yu., Kuzin D. Yu., Analysis of the modes of operation of natural ventilation systems of multi-apartment residential buildings in the warm period of the year. Volzhsky scientific journal. vol. 4 (40), pp. 26-32. (2016)

13. Bodrov M.V., Kuzin V.Yu., Morozov M.S., Improving the energy efficiency of systems for providing microclimate parameters for multi-family residential buildings. Housing construction vol. 6, pp. 48-50 (2015)

14. Bodrov M. V., Boldin V. P., Kuzin V. Yu., Kucherenko M. N., Determination of the actual performance of natural ventilation systems with a vertical prefabricated collector 
of multi-apartment residential buildings. Volzhsky scientific journal. vol. 1 (33), pp. 5459 (2015)

15. Andrey Rymarov, Energy saving in the formation of covered courtyards. E3S Web of Conferences EKO-DOK vol. 100, pp. 00072 (2019)

16. Kuvshinov Yu. Ya, Bodrov M. V., Methodological bases of designing systems for providing microclimate parameters of industrial agricultural buildings. MGSU Bulletin. vol. 2-2, pp. 234 (2011)

17. Rymarov Andrey, Parfenteva Natalia, Valančius Kęstutis, Sabina Paulauskaitè, Violeta Misevičiūtè, Gaseous and thermal analysis of winter garden used for air regeneration throughout office buildings. Journal of Environmental Engineering and Landscape Management vol. 26, issue 3, pp.195-201 (2018)

18. Abramkina D. V., Formation of the aeroion regime of residential premises. Scientific review. vol. 11, pp. 48-51 (2017)

19. Abramkina D. V., Calculation of hourly values of the heat load on the air conditioning system with automated control. Natural and technical sciences. Vol. 6 (108), pp. 138140 (2017)

20. Malyavina E. G., Frolova A. A., Analysis of annual energy consumption for heating and cooling of an office building. Ventilation, Heating, Air Conditioning, Heat Supply and Building Thermal Physics (ABOK). Vol. 1, pp. 68-75 (2017) 